\title{
The Influence of Ultrasonic Treatment on the Properties of Schottky Diodes
}

\author{
I. G. Pashayev \\ Physical Faculty, Chair of Physical Electronics, The Baku State University, Baku, Azerbaijan \\ Email: islam.pashayev@yandex.com
}

Received June 29, 2013; revised July 29, 2013; accepted August 6, 2013

Copyright (C) 2013 I. G. Pashayev. This is an open access article distributed under the Creative Commons Attribution License, which permits unrestricted use, distribution, and reproduction in any medium, provided the original work is properly cited.

\begin{abstract}
The given work studies the reason of the change of a superfluous current near crystallization temperature of an amorphous $\alpha \mathrm{PbSb}$ metal alloy and at the same time founds out the influence of ultrasonic processing (USP) on the properties of $\alpha \mathrm{PbSb}-\mathrm{nSi}$ solar elements (SE), made by Shottki diodes technology (ShD) with a metal alloy. It is found that occurrence of a superfluous current $\alpha \mathrm{PbSb}-\mathrm{nSi} \mathrm{ShD}$ under the influence of thermoannealing is connected with changes of structure of an amorphous film of metal at transition in a polycrystalline condition. VAC damaged $\alpha \mathrm{PbSb}-\mathrm{nSi}$ Sh Dare very sensitive to annealing time. Eventually, even at room temperature, level of a superfluous current decreases, i.e. "the wound" put by mechanical damage sort of heals, restoration process occurs the faster, the higher the annealing temperature is. Function of $\gamma_{t}$ annealing parameters changes in an interval $\left(0 \leq \gamma_{t} \leq 1\right)$ and the influence USP on photo-electric properties $\alpha \mathrm{PbSb}-\mathrm{nSi}$ SE depends on the chosen UIT mode.
\end{abstract}

Keywords: Photosensitivity; Barrier Properties; Amorphous Metals; Diodes Shottki; Superfluous Currents; Degradations; Ultrasonic Influence; Silicon Solar Elements

\section{Introduction}

In the literature devoted to physics and technology of contact metal-semiconductor, the processes occurring in contact piece are extensively studied, and it is considered that all these processes are connected with the semiconductor. The role of metal in most cases is neglect. Influence of metals and their crystal structure on the processes which take place in contact piece, either is not considered, or is badly studied. To identify the role of metal ShD properties [1-4] have been studied. In late XX centuries, interest in ShD, made with application of films of metals and metal alloys with amorphous structure $[2,4,5]$ has increased. The reason of such interest is that application metal films with amorphous structure allows to make $\mathrm{ShD}$ with important application properties. Advantage of application of amorphous metals also lies in the fact that due to the absence of granular structure and boundaries of grains in amorphous films a more homogeneous demarcation must be formed, and as effect of it, ShD should have properties, close to the ideal ones. Besides, there are messages that amorphous films of metals well play a role of diffusive and electric barriers in microelectronic structures. The present activity is devoted to stu- dying of change of a superfluous current in a $\alpha \mathrm{PbSb}-\mathrm{nSi}$ $\mathrm{ShD}$ close to the temperature of crystallization of an amorphous metal alloy, and simultaneously to studying of influence of UIT on the properties of a $\alpha \mathrm{PbSb}-\mathrm{nSi} \mathrm{SE}$ sample made on $\mathrm{ShD}$ technology with a metal alloy. In certain cases, under the influence of various factors, at low direct voltage superfluous current occurs in $\mathrm{ShD}$ there due to the degradation of the current-voltage characteristic $[4,6]$. In our experiment in $\alpha \mathrm{PbSb}-\mathrm{nSi} \mathrm{ShD}$ the superfluous current appears at temperature near $573 \mathrm{~K}$, as is shown in Figure 1. Along with temperature change structural changes take place [7] in amorphous metal films which appear at small direct voltage of VAC degradation. In this connection it is of interest to study degradation (superfluous currents) properties which have arisen under the influence of thermoannealing, and also study the influence of ultrasonic effect on photo-electric and electrophysical properties of semiconductor diodes and devices of this kind. Lately interest in a problem of purposeful change of physical properties of semiconductor materials does not weaken. Practically in all publications on this subject a question on particular gears of this effect remains unclear [8-12].

As ultrasonic effect is an effective mode of increasing 


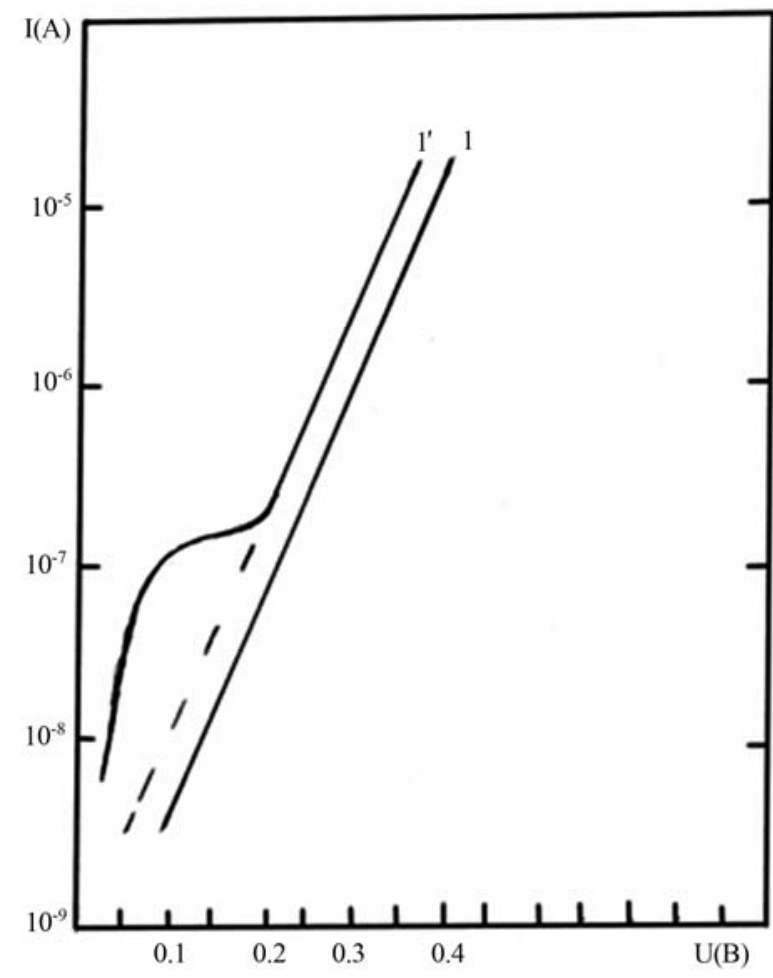

Figure 1. Current-voltage characteristic of $\alpha \mathrm{PbSb}-\mathrm{nSi}$ Shottki diodes 1-before and 1'-after a thermoannealing at 473 K.

the internal energy of solids, depending on absorption coefficient and intensity of ultrasound, various structural changes influencing both the photo-electric, electrophysical properties of materials and plastic deformation process are possible.

\section{Experimental Process}

For manufacturing a ShD a p-type silicon plate with orientation (III) and specific resistance of $0.7 \mathrm{Om} \cdot \mathrm{cm}$ was used. The matrix contained 14 diodes which areas changed in the range from 100 to $1400 \mathrm{mkm}^{2}$. The contact piece area in our case was equal to $300 \mathrm{mkm}^{2}$. A $\alpha \mathrm{PbSb}$ metal alloy was deposited by the method of electron beam evaporation from two sources. The $\alpha \mathrm{PbSb}$ alloy has been chosen from those reasons that both components are widely applied in microelectronics, and the alloy is technological. A possibility of obtaining films of this alloy with amorphous structure was reported in paper [7]. The speeds of evaporation of components were chosen so that the film structure corresponded to alloy $\mathrm{Pb}_{5} 2 \mathrm{Sb}_{48}$ as in paper [7] it was informed that such alloy is inclined to amorphization.

The thermoannealing of diodes was conducted at temperatures from $323 \mathrm{~K}$ to $573 \mathrm{~K}$ during identical periods of $t=10$ minutes

The structure of a film of an alloy before and after an- nealing was supervised by the radiographic analysis.

In Table 1, characteristics of $\alpha \mathrm{PbSb}-\mathrm{nSi} \mathrm{SE}$ sample before and after UIT are presented at various modes. It is obvious from Table 1 that after UIT-1 $\left(\mathrm{W}_{\mathrm{UIT}}=0.55\right.$ $\mathrm{W} / \mathrm{cm}^{2}, t=200 \mathrm{~min}$., $\mathrm{f}_{\mathrm{UIT}}=25 \mathrm{MHz}$ ) the return current of the sample was increased by few times. The following stage of ultrasonic processing UIT-2 $\left(\mathrm{W}_{\text {UIT }}=0.15 \mathrm{~W} / \mathrm{cm}^{2}\right.$, $t=200 \mathrm{~min}$., $\mathrm{f}_{\mathrm{UIT}}=25 \mathrm{Mhz}$ ) has led to insignificant reduction of a return current. It, in our opinion, testifies the improvement of a defective condition of base SE. The subsequent stage of ultrasonic processing of sample UIT-3 $\left(\mathrm{W}_{\mathrm{UIT}}=25 \mathrm{~W} / \mathrm{cm}^{2}, t=90\right.$ minute, $\left.\mathrm{f}_{\mathrm{UIT}}=25 \mathrm{MHz}\right)$ has one more time led to increase in a return current though after UIT with such power a breakdown of an SE or at least, increase of return current by few times was expected.

\section{Results and Their Discussion}

Figure 1 is presented current-voltage charachteristics for $\alpha \mathrm{PbSb}-\mathrm{nSi} \mathrm{ShD}$ before and after annealing at $473 \mathrm{~K}$. It is obvious from the schedule that after a thermoannealing at small direct voltages superfluous current appears. It is known that amorphous films of metals at certain temperatures change structure and turn into a polycrystalline state [7]. Hence, it is possible to assume that occurrence of a superfluous current in ShD after annealing at temperature of $473 \mathrm{~K}$ and above is connected with change of structure of a metal film of an alloy. Really, inspection of structure of $\mathrm{Pb}_{52} \mathrm{Sb}_{48}$ metal film on installation DROH-2 before and after annealing at temperature 573 showed that the film of metal turns from an amorphous or quasiamorphous state into polycrystalline (Figure 2). As can be seen from the picture, the film of alloy $\mathrm{Pb}_{52} \mathrm{Sb}_{48}$ before annealing has amorphous structure. Such conclusion is made on such basis that crystals have a strongly featured series of maxima and minima, which indicates not only a correct arrangement of the nearest atoms, but also about existence of a distant order.

Figure 3 is presented the voltage-current characteristics for $\alpha \mathrm{PbSb}-\mathrm{nSi} \mathrm{ShD}$, degraded artificially by means

Table 1. Photo-electric parameters of $\alpha \mathrm{PbSb}-\mathrm{nSi}$ the sample before and after $U S P$ at $R=100 \mathrm{~W} / \mathrm{cm}^{2}$ and $T=300$.

\begin{tabular}{|c|c|c|c|c|}
\hline $\begin{array}{c}\text { condition of } \\
\text { the sample }\end{array}$ & Before UIT & $\begin{array}{c}\text { After UIT } \\
-1\end{array}$ & $\begin{array}{c}\text { After UIT } \\
-2\end{array}$ & After UIT 3 \\
\hline $\mathrm{I}_{\text {к.3. }}, \mathrm{mA}$ & 27.60 & 23.87 & 24.56 & 21.00 \\
\hline $\mathrm{U}_{\mathrm{xx}}, \mathrm{V}$ & 0.517 & 0.500 & 0.501 & 0.483 \\
\hline$\eta, \%$ & 9.182 & 7.691 & 8.092 & 6.540 \\
\hline $\mathrm{I}_{\mathrm{o} \sigma}, \mathrm{A}$ & $9.4 \times 10^{-6}$ & $4.5 \times 10^{-5}$ & $4.2 \times 10^{-5}$ & $1.3 \times 10^{-4}$ \\
\hline A & 2.25 & 2.60 & 2.58 & 2.78 \\
\hline
\end{tabular}




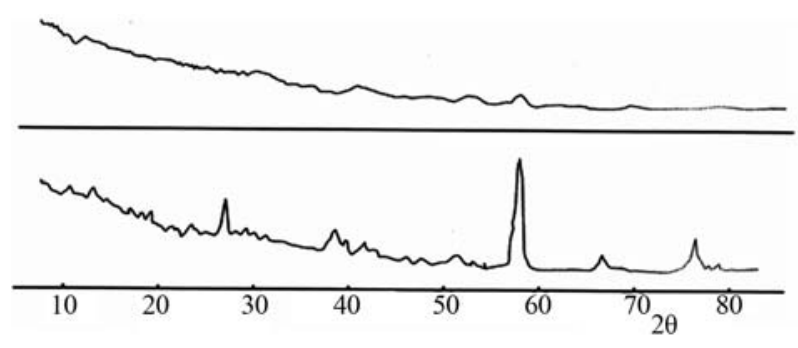

Figure 2. The X-ray structural analysis of amorphous metal films $\alpha$ PbSb. 1-to, 1'-after a thermoannealing at $473 \mathrm{~K}$.

of a diamond hardometer PMT-3. The non-uniformity on border section BS was created artificially. The diamond needle of the adapter represents a correct quadrangular pyramid with a corner between opposite sides of $136^{\circ}$. The area of the dislocated sections was varied by change of load value $\mathrm{F}(50 \mathrm{~g})$ and quantities of violations $\mathrm{N}$ (1) before and after annealing at $473 \mathrm{~K}$ during some time: (1 - 17 s, $2-65$ s, $3-148$ s, $4-260$ s, $5-410$ s, $6-580$ s, $\mathrm{V}_{\text {rev }}=0.20$ ). Degrading properties of $\alpha \mathrm{PbSb}-\mathrm{nSi} \mathrm{ShD}$ after thermoannealing at temperatures from $323 \mathrm{~K}$ to 573 $\mathrm{K}$ were supervised by a method of removal currentvoltage characteristics both in forward direction, and return.

For the quantitative characteristic of recovery of a superfluous current under the influence of annealing, taking into account time, the following formula was applied:

$$
\gamma_{t}=\frac{I_{t}-I_{H}}{I_{o}-I_{H}}
$$

where $I_{H}$-current of a normal (intact) diodes Shottki,

$I_{o}$ Diodes directly after influence if identer $(t=0)$,

$I_{t}$ Damaged diodes, annealed during $t \mathrm{sec}$,

$\gamma_{t}$ Characterises relative recovery of a superfluous current under the influence of a thermoannealing during period $t$.

As is shown in Figuer 4, $\gamma_{t}$ essentially depends both on $\mathrm{T}_{\mathrm{ann}}$, and $t$. Value $\gamma_{t}$ at various values of temperature of annealing and depending on $t$ of annealing changes in an interval $0 \leq \gamma_{t} \leq 1$. From this it is seen that, first, the milestone of process of an annealing occurs for short initial periods, secondly, the milestone of process of annealing "cures" (restores properties) the damaged diodes. Current-voltage characteristic of $\alpha \mathrm{PbSb}-\mathrm{nSi} \mathrm{ShD}$ is very sensitive to the time of annealing. Eventually, even at room temperature, level of a superfluous current decrease, i.e. "the wound" put by mechanical damage kind of heals. Recovery process occurs the faster, the higher the annealing temperature is. It is obvious from the figures, that certain level of annealing is reached at various parameters of annealing: annealing level $\gamma_{t}=0.1$ at $\mathrm{T}_{\mathrm{ann}}=473 \mathrm{~K}$ is reached during $t=200$ second, and at $\mathrm{T}_{\mathrm{ann}}=523 \mathrm{~K}$ during $t=9$ second.

In Table 1, the photo-electric parameters determined

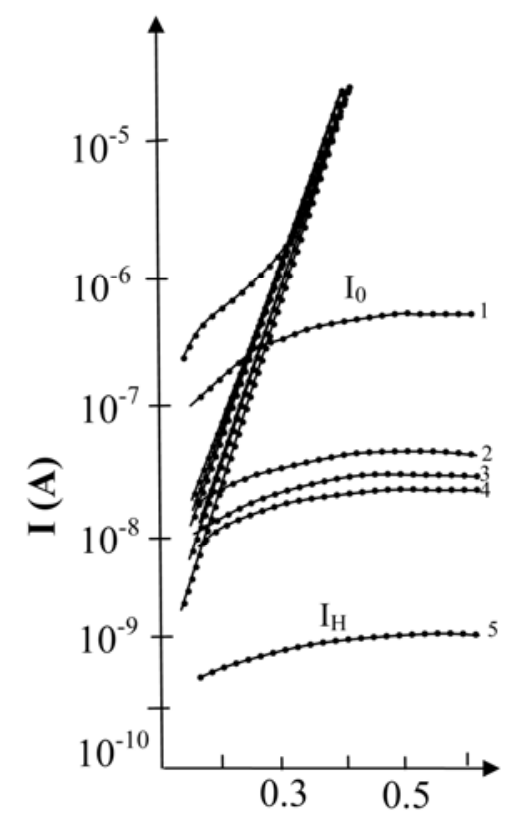

Figure 3. Current-voltage characteristic of $\alpha \mathrm{PbSb}-\mathrm{nSi} \mathrm{ShD}$ in normal, artificial degraded and annealed conditions. $\mathbf{I}_{\mathrm{H}}$-Normal (intact) diodes Shottki, $\mathbf{I}_{\mathbf{0}}$-diodes directly after the influence of identer $(t=0),(\mathrm{V}=0.20 \mathrm{v})$

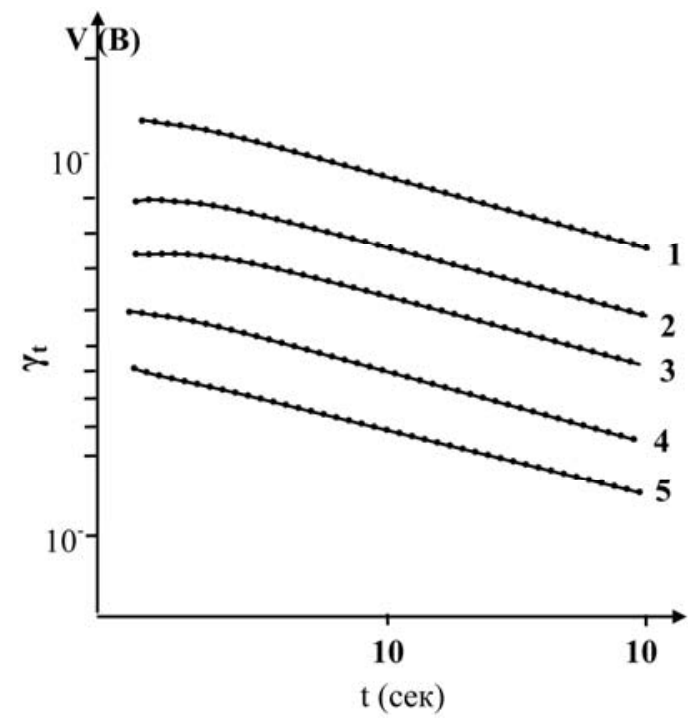

Figure 4. A relation of $\gamma_{t}$ from annealing time at various values of temperature of annealing, $1-473 \mathrm{~K} ; 2-498 \mathrm{~K}$; $3-523 \mathrm{~K} ; 4-548 \mathrm{~K}$; 5-573 K.

from the above described experiments are presented: $I_{\text {s.c. }}$ short circuits, $\mathrm{U}_{\mathrm{x} . \mathrm{x}}$-open-circuit voltage, $\eta$-efficiency, $\mathrm{I}_{\mathrm{ret}}-\mathrm{a}$ return current, $\mathrm{A}$ - dimensionless factor of the sample. In the table are represented values of these parameters after each stage of ultrasonic processing of the sample. Such built of the table allows to track on what value photo-electric parametres will change with supply on the sample of an ultrasonic wave with stringently set power, frequency and during set time. In investigated silicon SE, 
there is effective absorption of UIT in the places containing imperfections of a crystal lattice. The last represent dot defects and their complexes, and also claster formations and dispositions. As a result, there is a process of reorganisation of dot defects and their complexes possible.

\section{Conclusions}

Thus, it is possible to conclude that the superfluous current passes through mechanically dislocated areas of contact piece, and the reason of its occurrence is connected with violation of BS. It once again proves that occurrence of a superfluous current for $\alpha \mathrm{PbSb}-\mathrm{nSi} \mathrm{ShD}$ near temperature of crystallization of an amorphous metal alloy is connected with the change of structure of an amorphous film of metal at transition into a polycrystalline state. From the received results it is obvious that change of parameters of annealing occurs for short initial periods, and the milestone of the process of annealing "cures" the damaged diodes. Certain level of annealing is reached at various parameters of annealing, annealing level of $\gamma_{t}=0.1$ at $\mathrm{T}_{\mathrm{ann}}=473 \mathrm{~K}$ is reached during $t=200$ second, and at $\mathrm{T}_{\mathrm{ann}}=523 \mathrm{~K}$ during $t=9$ second

The results of conducted experiments show that UIT influences the character and degree of changes of the photoelectric and electrophysical properties of SE.

\section{REFERENCES}

[1] K. Mammadov, "Contact Piece Metal-Semiconductor with an Electrical Field of Stains," Baku State University, Baku, 2004.

[2] SH. G. Askerov, SH. G. Aslanov and I. G. Pashayev, "Electrophysical Properties of Barrier Structures on the Basis of Silicon with an Amorphous Metal Alloy Aluminium- Nickel," The Electronic Engineering, Microelectronic Devices, Vol. 6, No. 78. 1989, p. 46.

[3] N. A. Torhov, "Nature of Direct and Return Currents of Saturation in Contact Pieces Metal-Semiconductor with a
Barrier of Shottki," Semiconductors, Vol. 44, No. 6, 2010, p. 767

[4] SH. G. Askerov, "Influence of Degree of Non-Uniformity of Border of Section on Electrophysical Properties of Structures Metal-Vacuum and Metal-Semiconductor," the Thesis for a Doctor's, Baku State University, Baku, 1992. p. 399.

[5] N. A. Gusejnov, S. G. Askerov, J. M. Olih, et al., "Processing of the Irradiated Solar Cells by Means of Ultrasound," Geliotehnika, No. 2, 2006, p.17.

[6] A. N. Gontaruk, D. V. Korbutjak and E. V. Korbut, "Degrade-Relaxation Phenomena in Light Emitting $p-n$ Structures on the Basis of Photodiode Gallium, Stimulated by Ultrasound," Letters in JTF, Vol. 24, No. 15, 1998, p. 64.

[7] K. Suzuki, K. Hasimoto and X. Fudzimori, "Amorphous Metals," M: Metallurgy, 1987.

[8] I. B. Ermolovich and V. V. Milenin, "Konakovo of River $\mathrm{B}$, et al., "Influence of Ultrasonic Processing on Microprocesses of Formation of Barriers of Shottki of Heterosystems $\mathrm{M}-\mathrm{n}-\mathrm{n}+\mathrm{GaAs}(\mathrm{M}=\mathrm{Pt}, \mathrm{Cr}, \mathrm{W})$," Technical Physics Letters, Vol. 22, No. 6. 1996, p. 33.

[9] G. D. Melebaeva, Д. Melebaev, J. V. Rud and V. J. Rud "Photosensitivity of Barriers of SHOTTKI Ni-GaAs," Semiconductors, Vol. 43, No. 1, 2009, p. 34

[10] I. V. Ostrovskij, L. P.Steblenko and A. B. Nadtochy, "Formation of the Superficial Hardened Layer in Nondislocated Silicon at Ultrasonic Processing," Semiconductors, Vol. 34, No. 3. 2000, p. 257

[11] The Parchinsky Item B., S. I. Vlasov and L. G. Ligaj, "Probe of Influence of Ultrasonic Effect on Generating Characteristics of Previously Irradiated Border of Silicon —Dioxide Silicon," Semiconductors, Vol. 40, No. 7, 2006, pp. 829- 832.

[12] The Parchinsky Item B., S. I. Vlasov, R. A. Muminov, et at., "Influence of Ultrasound on Parameters of Structures of Metal-Dielectric-Semiconductor," Letters in JTF, Vol. 26, No. 10. 2000, p. 40. 